\title{
Rehabilitation after preterm labor and pregravid preparation is the basis for improving perinatal outcomes
}

\begin{abstract}
Women who give birth prematurely have many genital and extragenital diseases. We noticed a high incidence of pelvic organs diseases in the examined women after premature birth in the end of the lactation period compared with patients who gave birth on time. There was a violation of the biotope of the vagina 5.5times more often, endometrial disease 9.6times; hyperplastic processes: leiomyoma of the uterus 2.7 times more often. In women who gave birth prematurely extragenital diseases such as iron deficiency anemia were detected 3.5times more often, gastrointestinal tract diseases 1.5times, urinary tract diseases 1.6times. Such diseases as obesity, hypertension and autoimmune thyroiditis were diagnosed only in women after premature birth. This requires the recovery of women after preterm labor, both the elimination of the disorders of reproductive system and compensation for extragenital diseases.
\end{abstract}

Keywords: health of women after premature birth, genital diseases, extragenital diseases, rehabilitation
Volume 3 Issue 4 - 2017

\begin{abstract}
Alina V Solovyova, ' Viola Gace, ${ }^{2}$ Kristina S Ermolenko ${ }^{3}$

'Doctor of medicine, professor of the Department of obstetrics and gynecology with the course of perinatology of the Peoples, Friendship University of Russia (RUDN University), Russia 2Post-graduate (PHD) student of the Department of obstetrics and gynecology with the course of perinatology of the Peoples Friendship University of Russia (RUDN University), Russia ${ }^{3}$ Candidate of Medical Sciences, assistant of the Department of obstetrics and gynecology with the course of perinatology of the Peoples Friendship University of Russia (RUDN University), Russia
\end{abstract}

\begin{abstract}
Correspondence: Alina V Solovyova, Doctor of medicine, professor of the Department of obstetrics and gynecology with the course of perinatology of the Peoples, Friendship University of Russia (RUDN University), Moscow, Russian Federation, Russia,Tel+79854477928, Email av_soloveva@mail.ru
\end{abstract}

Received: November 20, 2017 | Published: December 22, 2017

\section{Introduction}

The low level of reproductive age women health reveals the extraordinary value of every desired pregnancy. ${ }^{1}$ Targeted prevention of possible obstetric complications is the most effective way to reduce reproductive losses. ${ }^{2}$ One of the priorities of modern medicine is the rehabilitation of women after a stiff pregnancy, ${ }^{3}$ miscarriages, premature births. The improvement of preventive measures taken at the preconception stage $e^{4}$ is also important since it is practically impossible to influence the risk factors during pregnancy. ${ }^{5}$ The aim of the survey was to study the state of women's health after preterm labor and treatment of their diseases, considering the given relevance of rehabilitation after unfavorable perinatal outcomes.

\section{Materials and methods}

In accordance with the goals and objectives was developed a research program to identify the medical and social characteristics of the category of women after preterm delivery and rehabilitation. This work was carried out for the period from 2013 to 2016 at the clinical bases of the Department of obstetrics and gynecology with the course of perinatology of the Peoples' Friendship University of Russia (Head of the Department - Corresponding Member of Russian academy of science, Professor V.E. Radzinskiy) - 25 maternity hospital of Moscow city hospital No. 1 and branch No. 2 of Moscow city hospita No. 24.

The subject of this study were 49 women at the end of the lactation period: the first group - 29 women after preterm labor and the second group or the group of control - 20 patients after term labor.

\section{Results}

Observed patients were at the age of 18 to 41years (Table 1). The mean age was $29.3 \pm 1.2$ years and the mean age in the control group was $27 \pm 1.5$ years $(p<0.05)$. The analysis of professional background revealed that the number of housewives is 2.6 times higher in the group with preterm delivery, compared to women who gave birth on time where employees were more likely to meet. 3 women with preterm labor and 3 women in the control group used to smoke which was $10.3 \%$ and $15 \%$ of the total number of subjects in each group respectively.

Evaluation of the patient's medical history revealed differences. Primigravidas were more common among women with term delivery - $8(40 \%)$, women after preterm delivery $11(37.9 \%)$, multigravidas were $30(62.2 \%)$ but only 13 of them $(26.7 \%)$ were patients with preterm labor in anamnesis (Table 2).

The frequencies of spontaneous termination of pregnancy consist in $8(27.5 \%)$ patients with a history of preterm labor in comparison with women who gave birth on time $3(15 \%)$ (Table 2). 12(41.3\%) women from the first group and $7(35 \%)$ from the second one had a history of artificial abortions. There were no previous preterm labor between women of the control group, while in women with preterm labor 3 of them $(10.3 \%)$ were present.

Extragenital diseases were detected In 28(95.3\%) women after preterm delivery while among women who gave birth on time they were found in 15(75\%) (Table 3). Thus, extragenital diseases in women with preterm labor were 1.3 times more common than in women with term labor $(\mathrm{p}<0.05)$. 
The most frequent diseases in women after preterm labor were mild iron deficiency anemia in 10(34.5\%), diseases of the gastrointestinal tract in $11(37.9 \%)$, urinary tract diseases in $9(31 \%)$, hypertension in $4(13,7 \%)$. In the same group obesity was found in $6(20.7 \%)$ and autoimmune thyroiditis in $5(17.2 \%)$, in comparison with women after timely delivery these diseases did not occur.

In $6(20.7 \%)$ women after preterm labor with a BMI $>=30 \mathrm{~kg} /$ $\mathrm{m}^{2} \mathrm{a}$ blood test with an assessment of the glucose profile determined an increase in the glucose concentration - the average values were $8.38 \pm 0.35 \mathrm{mmol} / \mathrm{L}$, the level of insulin $11,2 \pm 2.2 \mu \mathrm{U} / \mathrm{ml}$, HOMA-IR $4.17 \pm 1.75$. In women after term delivery obesity was not noticed, the glucose level was within the physiological norm and averaged $5.2 \pm 0.2 \mathrm{mmol} / \mathrm{L}$, the insulin concentration was on average $8.2 \pm 0.75 \mu \mathrm{U} /$

\section{ml, HOMA-IR - $1.9 \pm 0.3$.}

The study of the structure of gynecological morbidity allowed to find reliable differences between the groups. In 12(41.3\%) women after preterm labor was observed menstrual dysfunction when in the control group only $2(10 \%)$ women had this disorder (Table 4). Each second patient with preterm labor had a history of inflammatory pelvic disease, which was twice the incidence of these diseases in patients who gave birth on time. This fact is not surprising considering the high incidence of uterine curettage during medical and spontaneous abortions in the absence of rehabilitation measures. Cystectomy due to endometriotic cysts was the most common surgical intervention. It was preceded in $2(6.8 \%)$ women with preterm labor and in $1(5 \%)$ patient with a term labor.

Table I Clinical and anamnestic data of the examined women

\begin{tabular}{llllllll}
\hline Groups & N & Age & Employees & Housewives & Students & Study and work & Smoke \\
\hline Group I & 29 & $29,3 \pm 1,2$ & $18 / 62,2 \% *$ & $8 / 27,5 \%$ & $2 / 6,8 \%$ & $1 / 3,6 \%$ & $3 / 10,3 \%$ \\
Group II & 20 & $27 \pm 1,5$ & $16 / 81 \%$ & $3 / 15 \%$ & $1 / 4 \%$ & - & $3 / 15 \%$ \\
\hline
\end{tabular}

*The reliability of differences between groups $(p>0.05)$

Table 2 Obstetric and gynecological history

\begin{tabular}{|c|c|c|c|c|c|c|c|}
\hline Groups & $\mathbf{N}$ & Primigravida & Primipara & Spontaneous miscarriage & Artificial abort & Term labor & Preterm labor \\
\hline Group I & 29 & I I/37,9\%* & $8 / 27,5 \%$ & $8 / 27,5 \% *$ & $|2 / 4|, 3 \% *$ & $10 / 34,4 \%$ & $3 / 10,3 \% *$ \\
\hline Group II & 20 & $8 / 40 \%$ & $4 / 20,0 \%$ & $3 / 15 \%$ & $7 / 35 \%$ & $8 / 40 \%$ & - \\
\hline
\end{tabular}

*The reliability of differences is found when comparing the total number of women with preterm and term labor $(p<0.05)$

Table 3 Structure of extragenital morbidity

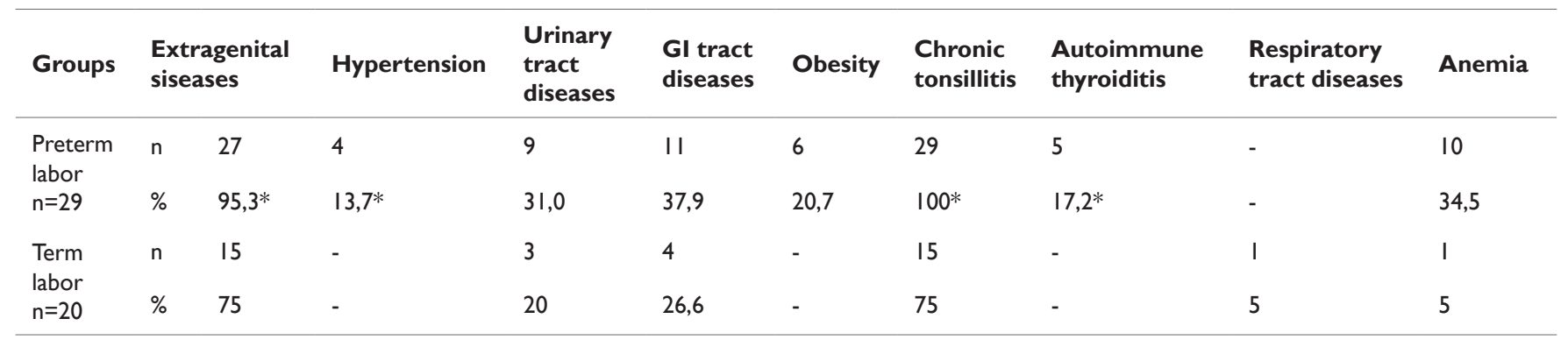

* The reliability of the differences was found in the comparison of groups I and II $(\mathrm{p}<0.05)$

Table 4 The structure of gynecological diseases in the examined women

\begin{tabular}{|c|c|c|c|c|c|c|c|}
\hline Groups & $\mathbf{N}$ & $\begin{array}{l}\text { Menstrual } \\
\text { disfunction }\end{array}$ & PID & Leiomyoma & Endometriosis & Ovary disfunction & Bacterial vaginosis \\
\hline Group I & 29 & $|2 / 4|, 3 \% *$ & $|5 / 5|, 7 \% *$ & $3 / 10,3 \%$ & $2 / 6,8 \%$ & $5 / 17,2 \% *$ & $19 / 65,5 \% *$ \\
\hline Group II & 20 & $2 / 10 \%$ & $5 / 25 \%$ & I/ $5 \%$ & $1 / 5 \%$ & - & - \\
\hline
\end{tabular}

* The reliability of differences was found when comparing the I group with the control group $(p<0.05)$

Bacteriological examination of the cervical discharge was performed in $49(100 \%)$ patients. The prevalence of opportunistic enterobacteria (E. Coli, fecal enterococcus) was noted in $4(13.8 \%)$ women after preterm labor and in $2(10 \%)$ patients of the second group. In $22.4 \%$ (11 patients), there was no any pathological microflora detected. In most cases the infection in patients after preterm labor was mixed.
Also we found an increase in testosterone level to $3.0 \mathrm{nmol} / 1$ in $3(10.3 \%)$ women after preterm labor. The concentration of other hormones (TSH, FSH, LH) was within the physiological norm.

According to the obtained data from the ultrasound investigation the widening of uterine cavity to a maximum of $0.7 \mathrm{~cm}$ was observed in $5(33.3 \%)$ patients after preterm labor and in $7(50 \%)$ women after term delivery. Also in $2(13.3 \%)$ patients of first group and in $1(7.1 \%)$ 
patient from the second one there was asymmetric expansion of uterine cavity. The heterogeneity of the structure of endometrium, the detection of clear hyperechogenic formations in the basal layer, with a maximum size of up to $0.1 \mathrm{~cm}$ and the presence of gas bubbles with the acoustic effect of the comet's tail were found in $6(40 \%)$ women in group I and 3(15\%) in group II. Most often there was a combination of several of the above ultrasound signs that allow the presence of chronic endometritis in these patients.
An increase in the anterior-posterior size of the uterus was detected in $5(33.3 \%)$ after preterm labor, while in the group after term labor it was not noticed (Table 5). Multiple myomatous nodes (interstitial-subserous node $5.0 \mathrm{~cm}$ in size and small interstitial nodes up to $2.0 \mathrm{~cm})$ were found in $1(5.9 \%)$ patient after preterm labor in ultrasound investigation, as well as in $3(20 \%)$ patients still from the group I were found small interstitial nodes measuring up to $2.0 \mathrm{~cm}$. In group II patients with this nosological form were absent.

Table 5 Data of ultrasound investigation of women after childbirth

\begin{tabular}{|c|c|c|c|c|c|c|}
\hline Groups & $\mathbf{n}$ & $\begin{array}{l}\text { Increase in the } \\
\text { anterior-posterior } \\
\text { size }\end{array}$ & $\begin{array}{l}\text { Widening ot uterine } \\
\text { cavity }\end{array}$ & $\begin{array}{l}\text { Heterogeneity of the } \\
\text { structure of endometrium }\end{array}$ & Leiomyoma & Follicular cysts \\
\hline Group I & 29 & $5 / 33,3 \%$ & $7 / 24,1 \%$ & $6 / 40 \%$ & $4 / 13,7 \% *$ & $8 / 27,6 \% *$ \\
\hline Group II & 20 & - & $8 / 40 \%$ & $3 / 15 \%$ & - & $3 / 15 \%$ \\
\hline
\end{tabular}

*significant differences $(p>0.05)$

Follicular cysts were observed in $8(16.3 \%)$ patients. $5(17.2 \%)$ among patients in the first group and in $3(15 \%)$ women of the second one $(p>0.05)$ (Table 5). After the examination each woman was offered an individual rehabilitation program. To the women suffering from type I and type II obesity a diet was recommended together with an endocrinologist. The drug dimethyl biguanide was prescribed in addition to adherence to dietary guidelines. Weight loss and blood glucose in patients were assessed as a marker of the effectiveness of rehabilitation therapy. All women with obesity had menstrual dysfunction such as oligomenorrhea which caused anxiety and dissatisfaction. Patients were assigned dydrogesterone in phase 2 of the cycle due to the lack of metabolic effects in this drug. By the 6 th menstrual cycle there was a decrease in body weight (minus $9.6 \pm 0.2 \mathrm{~kg}$ ) and regular moderate menstrual bleeding

In 3 women with diagnosed myomatous nodes larger than $4.0 \mathrm{~cm}$ was performed surgical treatment. Women with extragenital diseases found during this study such as hypertension, chronic cystitis and chronic gastritis, were examined from related specialists such as therapist, gastroenterologist, urologist aiming the correcting of the revealed disorders and prescribing appropriate treatment for the physiological course of pregnancy in the future.

Considering the fact that $8(27.6 \%)$ of women who had a history of premature birth had a combination of iron deficiency anemia and abundant uterine bleeding they were offered hormonal contraceptives. This led to a reduction in menstrual blood loss and restoration of iron

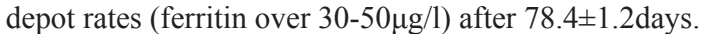

After complex rehabilitation therapy the number of women with uterine cavity expansion and the heterogeneity of the endometrium structure was halved. Menstrual cycle was restored. Reliable contraception and the normal biotope of the vagina were restored, and certain successes in the treatment of obesity were achieved.

\section{Discussion}

A low health index and a high incidence of pelvic disorders lead to disruption of implantation in the first trimester of pregnancy and the occurrence of later obstetric complications, including premature termination of pregnancy. ${ }^{6}$ The emergence of these disorders contributes to a number of factors among which the most important are the early onset of sexual activity, lack of the use of reliable contraceptives, ${ }^{7}$ high frequency of surgical abortion (abrasio cavi

uteri), the absence of rehabilitation measures after miscarriages, i.e. dysfunction of the endometrium ${ }^{8}$ and the presence of extragenital diseases. A large prevalence of anemia in women of reproductive age is associated often with abundant uterine bleeding which requires correction of the menstrual cycle. The effect of oral combined contraceptives is associated with the suppression of endometrial proliferation and the indirect reduction in the amount of blood loss. ${ }^{9}$

\section{Conclusion}

The causes of premature delivery are not defined but abnormalities in the state of women's health play a big role in the miscarriage of pregnancy. Healthy lifestyle, lack of obesity, i.e. healthy food, protected sex and the absence of abortion, contraception and the absence of abundant uterine bleeding are the main components of a woman's health and her future offspring.

\section{Acknowledgments}

None.

\section{Conflict of interest}

Author declares that there is no conflict of interest.

\section{References}

1. Radzinsky VE. Reproductive health: Proc. Help. 2011.

2. Arkhipova MP, Khamoshina MB, Chotchaeva AI, et al. Russia's reproductive potential: statistics, problems, prospects for improvement. Doktor RU. Russian; 2013;79(1):70-74.

3. Aylamazyan EK. Obstetrics: National leadership. In: Eilamazyan EK, Kulakov VI, editors. Moscow: Goetar - Media; 2013:366-367.

4. Arkhangelskiy VN. Fertility in modern Russia and its age model: dynamics and determination. In: Demographic development of Russia: the tasks of demographic policy and the strengthening of social support of the population. Materials of the All-Russian Scientific and Practical Conference. Moscow, Russia. 2011.

5. Chotchayeva AI. Preventive maintenance of the complicated course of pregnancy in the second trimester. Honey sciences. Russia; 2013. p. 19.

6. Galetskaya RA. Demographic development of Russia in the first quarter of the XXI century and the task of strengthening social support of the population. Problems of forecasting. 2011;6:120-130. 
7. Kulavskiy EV, Kulavskiy VA. Actual problems of preterm labor in modern obstetrics. Medical bulletin of Bashkortostan. 2011;6(1):49-52.

8. Cochrane Database of Systematic Reviews, 2010.
9. Rahman MM, Abe SK, Rahman MS. Maternal anemia and risk of inferior and middle-income countries: systematic review and metaanalysis. Clin Nutr. 2016;103(2):495-504. 